University of Wollongong

Research Online

Faculty of Law, Humanities and the Arts Papers (Archive)

Faculty of Arts, Social Sciences \& Humanities

$1-1-2019$

\title{
"Not like that, not for that, not by them": social media affordances of critique
}

Katrin Tiidenberg

Tallinn University

Andrew M. Whelan

University of Wollongong, awhelan@uow.edu.au

Follow this and additional works at: https://ro.uow.edu.au/lhapapers

Part of the Arts and Humanities Commons, and the Law Commons

Research Online is the open access institutional repository for the University of Wollongong. For further information contact the UOW Library: research-pubs@uow.edu.au 


\title{
"Not like that, not for that, not by them": social media affordances of critique
}

\author{
Abstract \\ This paper has two objectives: to explicate the sociotechnical conditions that facilitate critique on social \\ media platforms (specifically: Tumblr); and to operationalize a "working theory" from Foucault's \\ conceptualization of critique. We analyze resistant practices observed (in ethnographic study) in a Not \\ Safe For Work (NSFW) community on Tumblr, arguing that the potential for critique arises there at the \\ intersection of platform architecture and use cultures. Specifically, we show how critique emerges from \\ shared practices of ethics, most visibly enacted through what we call voluntary vulnerability and paying it \\ forward. This potential for critique is arguably at risk with Tumblr's recent NSFW ban.

\section{Disciplines} \\ Arts and Humanities | Law

\section{Publication Details} \\ Tiidenberg, K. \& Whelan, A. (2019). "Not like that, not for that, not by them": social media affordances of \\ critique. Communication and Critical/Cultural Studies, 16 (2), 83-102.
}




\section{"Not like that, not for that, not by them": social media affordances of critique}

This paper has two objectives. The first is to explicate the socio-technical conditions that facilitate critique on social media platforms (specifically: Tumblr), the second is to operationalize and utilize a "working theory" from Foucault's conceptualization of critique. We analyze resistant practices observed (in sustained ethnographic study) in a NSFW community on Tumblr and argue that the potential for critique arises there at the intersection of platform architecture and use cultures. More specifically, we show how critique emerges from shared practices of representation, interpretation, and interaction immanent to a particular practice of ethics most visibly enacted through what we call voluntary vulnerability and paying it forward. This potential for critique is arguably at risk with Tumblr's recent NSFW ban.

Keywords: critique; affordances; Tumblr; situational analysis; Foucault

\section{Introduction}

What makes reflexive problematization of how we are governed through various discourses possible, or even probable, on some social media platforms / communities, but not other? Do some platforms afford "voluntary insubordination" and "reflected intractability," which Michel Foucault defined as critique? ${ }^{1}$ This article maps the sociotechnical conditions that facilitate critique in a Not Safe For Work (NSFW; sexually explicit) Tumblr community. ${ }^{2}$ The community is characterized by expressions of (and support for) often-marginalized practices and subjectivities, alongside a critique of the sets of norms that regulate those practices and subjectivities. We argue that for critique to become possible, a particular constellation of conditions must emerge at the 
intersection of (a) social media platform architecture, (b) specific use cultures and (c) shared ethics. We suggest that between 2011 and 2017, this intersection of a-c on NSFW Tumblr afforded, or even incited, practices of parrhesia, self-reflection, and ultimately, critique. This article offers a granular analysis of the aforementioned constellation of conditions and practices by combining Michel Foucault's theoretical framework of critique, ${ }^{3}$ and extant communication scholarship on social media platforms and affordances. ${ }^{4}$

Our thesis emerges out of a pattern in Tiidenberg's previous ethnographic research with a NSFW community on Tumblr. ${ }^{5}$ From this research, it appears that regularly and pseudonymously creating, posting, liking, hashtagging, commenting on and reblogging sexual content (sexy selfies, erotic fiction and photography, diaristic posts of experiences and fantasies) over an extended period of time has an unanticipated consequence: participants begin questioning, resisting, and subverting various sets of norms. For this particular community, the norms they are resisting fall are under the aegis of hetero-, mono-, and body-normativity. ${ }^{6}$ Our participants share selfies of their bodies that may fall outside of the standards of thin/young/white and celebrate these as "sexy" or "beautiful." They share sexual experiences or fantasies that are kinky, queer, or polyamorous. ${ }^{7}$ They post about feeling and being sexual during pregnancy/breastfeeding/after 40/when menopausal. ${ }^{8}$ They develop hybrid relationships mixing friendship and romance. ${ }^{9}$ They refuse the diagnosis of postfeminist selfobjectification that some versions of feminism would have them embody because they post nudes. ${ }^{10}$ Their experiences become more meaningful over time and, where sustained, can be interpreted analytically as Foucauldian "voluntary insubordination" and "reflected intractability." 11 Posting nudes, for example, often transitions from a fairly self-centered aesthetic or thrill-seeking practice to a practice of self-awareness, 
searching for an inhabitable subject position as an aging woman, and on to an ethically and politically mindful practice of posting "for body-positivity." 12 Participating in NSFW on Tumblr can lead to participation in a particular ethic, most visibly enacted through what we describe as conscientious practices of voluntary vulnerability and paying it forward.

However, this result is not guaranteed. To inhabit this ethic and to arrive at a political stance of questioning and rejecting the normalization of specific sets of norms, our informants indicate that their participation in the community needs to happen in particular ways. Key to this are shared practices of interpretation, representation, and interaction. These shared practices become possible at the intersection of the platform as a technical and commercial infrastructure (its interface and Terms of Service (ToS)), and the particular culture of using the platform shared by this group (the practices of the community). Finally, and perhaps most importantly for this analysis, our informants link their experiences of critique explicitly to Tumblr. Nowhere else in their mediated or unmediated social contexts do they experience this process of coming to problematize certain sets of norms. Their capacity and motivation to question aspects of the status quo originates from this bounded networked space, but comes to permeate their disposition across contexts. For example, informants have, due to their experience with the NSFW community, stopped using "gay" as an everyday conversational denigrator, started calling out their interlocutors on casual misogyny, altered their corporeal practices, or ways of dress, joined activist groups, and so on.

Observing this made us curious about the relationship between how norms are made visible, reconstituted, and rejected, and the specific socio-technical architecture of a particular mediated space. Our participants are users of Facebook, Instagram, Twitter, Fetlife, Snapchat, and other platforms, but the impetus to problematize how they feel 
governed through dominant normative frameworks arose only through experiences with NSFW Tumblr. How this impetus for critique will change with the full effects of Tumblr's late-2018 NSFW purge remains to be seen: we address this in greater detail towards the end of the article.

We are not making totalizing generalizations about Tumblr. The confines of this essay do not permit thorough empirical explication of how specific norms come to be questioned; this has been done in previous work. ${ }^{13}$ What follows is a meta-analysis where we map the many experiences of enacting critical stances among our participants. Based on what these have in common, we conceptualize our participants' enactment of critique as relative to a specific set of perceived affordances.

\section{Conceptual framework}

\subsection{Foucault's critique}

There is extensive scholarship on the subversion and resistance of norms online: the creation of countersites, commons, safe spaces, countercultures, or counterpublics. ${ }^{14}$ Social media has been described as an arena particularly suitable for people to "critique and intervene in prevailing social, cultural, economic, and political conditions." 15 However, this potential for critique must be situated in broader social and political contexts -norms of respectful dialogue or criteria for the production of "facts" are also demonstrably resisted — and depend on definitions of critique. ${ }^{16}$ In this section, we briefly sketch our interpretation of a Foucauldian model of critique that our analysis relies on (Figure 1). 


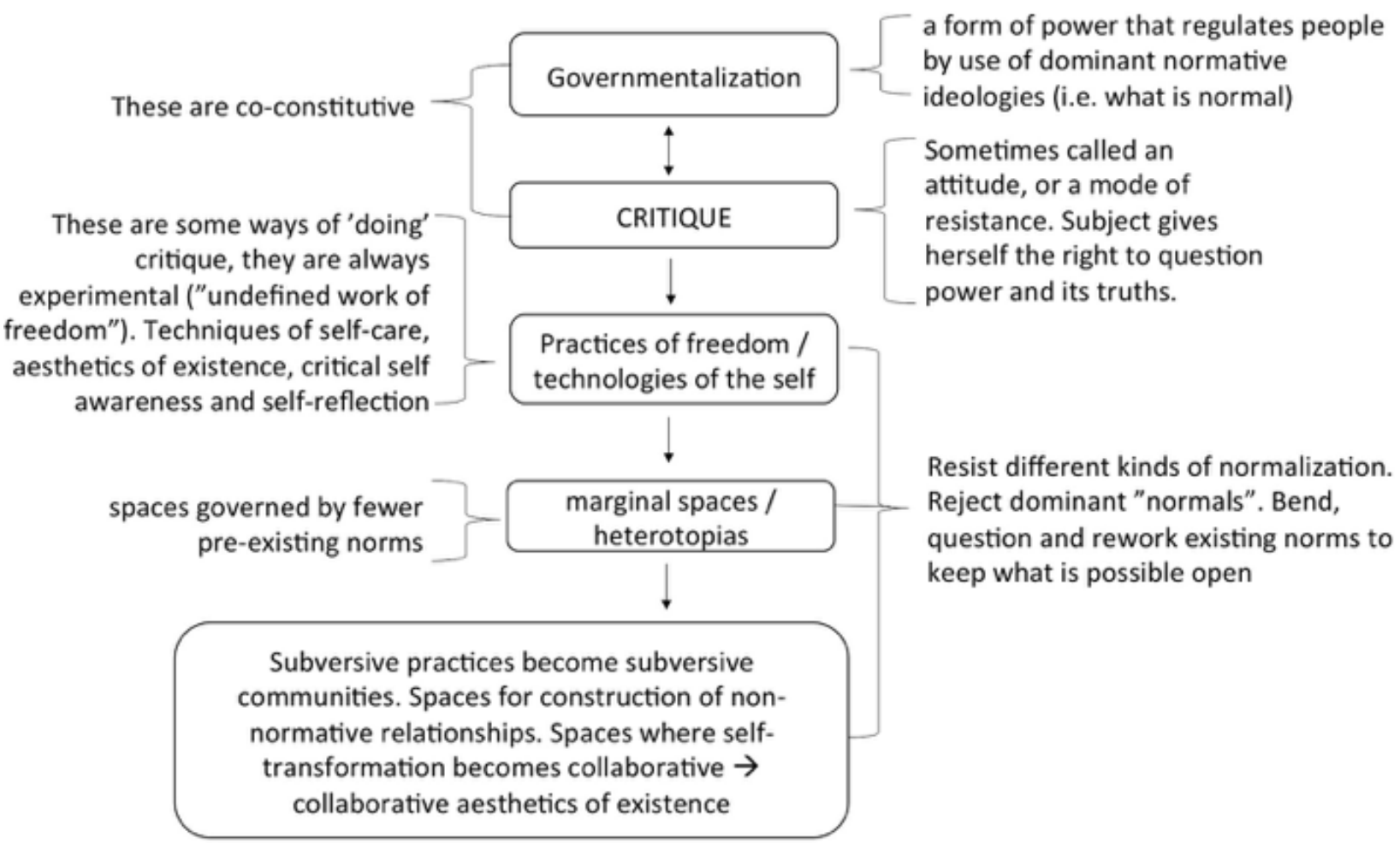

Figure 1: Conceptual map of Foucault's critique.

When Foucault talks about critique, he focuses on the relations between power, truth, and the subject. He writes: "critique is the movement by which the subject gives himself the right to question truth on its effects of power and question power on its discourses of truth. Well, then!: critique will be the art of voluntary insubordination, that of reflected intractability." ${ }^{17}$ For Foucault, critique is a practice: an active doing of something. It involves questioning that which seems inevitable (including some sets of norms), reflecting on "entrenched ways of acting and reacting" to reveal "the nonnecessity of present ways of thinking, doing and being"18 Critique thereby challenges the production of knowledge and limits authority. ${ }^{19}$

In Foucault's thinking, critique is co-constitutive with governmentalization (or governmentality). Governmentalization is a form of power operating through the "conduct of people, the way they behave." ${ }^{20}$ It is concerned with how and by whom to 
be governed (and how to govern oneself). It is the "movement through which individuals are subjugated in the reality of a social practice through mechanisms of power that adhere to a truth."21

For Foucault, modern, pastoral power works through:

i. discipline, functioning through normation (subjugating people to pre-existing norms, sometimes called "anatomo-politics") centered on the individual body, and

ii. biopower, functioning through normalization (regulating populations through comparison to imaginary statistical averages), centered on the species body. ${ }^{22}$ Together, from the 17th century onwards, these two mechanisms of power generate the "normal," intervene in people's lives, produce conformity, legitimize existing power relations, and normalize some norms until they appear natural and necessary. ${ }^{23}$

A Foucauldian conceptualization of governmentalization is entangled with the notion of sexuality. Referring to anatomo-politics and biopower (i and ii in the previous paragraph), Foucault writes: "sexuality has always been the site where the future of our species, and at the same time our truth as human subjects, are formed." ${ }^{24}$ Foucault's conception of sexuality as a vehicle for the production of subjectivity "through structures of moral and political exclusion" first arises in History of Madness. ${ }^{25}$ Here, Foucault observed that the modern age consigned all love/sex into binaries governed either by reason or unreason, placing within "all sexuality an obligation to choose." 26 Homosexuality, perversion, and other sexual practices later described as outside of the "charmed circle" were assigned to the category of unreason, and forced to take their place "in the stratifications of madness." ${ }^{27}$ Foucault later explicated this thesis on sexuality as an especially "dense transfer point for relations of power." ${ }^{28}$ He noted an explosion of discourse on sex at the end of the $17^{\text {th }}$ century: a "political, economic and 
technical incitement to talk about sex... in the form of analysis, stocktaking, classification, and specification." ${ }^{29}$ Truth about sex and the subject was produced through rituals of confession adapted to rationality and scientific discourse. Foucault calls this scientia sexualis. The "regulated and polymorphous incitement to discourse" of scientia sexualis worked with various knowledge/power strategies (e.g. hysterization of women, sexualization of children, socialization of procreative behaviors, and psychiatrization of perversions) and lead to sex becoming, at the turn of the $19^{\text {th }}$ century, "a matter that required the social body as a whole, and virtually all of its individuals, to place themselves under surveillance." ${ }^{30}$

Foucault's model of critique is not about rejecting all norms or all power:

knowledge/power is multiplicitous and relational. Instead, critique is about rejecting the totalizing effects of the normalization of some sets of norms, and thereby finding ways to practice forms of freedom. Critique, in the classic formulation, is about "how not to be governed like that, by that, in the name of those principles, with such and such an objective in mind and by means of such procedures, not like that, not for that, not by them." ${ }^{31}$ By questioning that which appears necessary and natural, critique gives impetus to "the undefined work of freedom." 32 Practices of freedom are experimental, and have an important ethical component. ${ }^{33}$ When our practices are informed by reflection, freedom takes the form of ethics. ${ }^{34}$ Freedom, self-care, critical self-awareness, and ethics are intertwined. ${ }^{35}$ By questioning what seems inevitable about one's self and being-in-the-world, critical self-awareness leads to the possibility of ethical transgression, results in self-reinvention, and becomes a practice of critique and freedom. Importantly, this is not a movement that culminates in an end point: it is an unfolding, ongoing dynamic. 
Foucault argued that there are already interactional situations and marginal spaces (heterotopias) governed by fewer pre-existing norms (he used the examples of $\mathrm{S} / \mathrm{M}$ clubs in San Francisco, and homosexual relationships in the $70 \mathrm{~s} / 80$ s). In these situations, new rules are negotiated, new power relations gel, and new relationships and subjectivities emerge. ${ }^{36}$ Importantly for Foucault, these new power relations, unlike those in accord with dominant norms, are explicitly fluid, open to transgression, or marked by local boundaries (e.g. participants know the boundaries of a "scene" in a $\mathrm{S} / \mathrm{M}$ club). ${ }^{37}$ These marginal spaces are both forms of localized resistance to normalization and challenges to the excessive normalization of relationships on a larger scale. ${ }^{38}$ They are valuable for their capacity to foster alternative models of human freedom. Over the past two decades, queer theoretical work (e.g. on adult businesses in the context of the Wolfenden Committee or NYC zoning laws) and internet scholarship (e.g. on cyberspace as a heterotopia) have further analyzed the possibilities of, and power struggles over, such spaces of subversion. ${ }^{39}$

\subsection{Incitement to critique}

Having outlined a definition of critique, we now turn to conceptualize social media platforms as spaces wherein this critique might be practiced. In Foucauldian terms we will explore the technical and social incitements to critique on NSFW Tumblr, with the following proviso in mind. Foucault used the term "incitement" to refer to the rationalconfessional discourse on sex mandated by knowledge/power structures on a grand scale. ${ }^{40}$ The abundance of sexual discourse in the community we study is neither central to our argument, nor at the scale Foucault indicated by "incited." We suggest -and hope it will be taken up for further research — that the socio-technical conditions for problematizing dominant sets of norms hold even if different (i.e. non-sexuality-related) normative ideologies are questioned. We are not interested in how discourse on sex is 
incited on Tumblr, but rather how the convergence of technical and social conditions incites practices that qualify as critique per se. NSFW practices are relevant here not for what they indicate regarding sexuality, but because they inhabit a normatively marginal status within the arena of mediated practices and content (evidenced, for example, in that most people posting nudes prefer to do so without including their face or full name).

We construe social media platforms as microsystems where technology, users, and use practices, content, governance, and business models interconnect. Such microsystems have particular affordances for specific practices. ${ }^{41}$ We thus operationalize the broader Foucauldian theoretical model of incitements through the conceptual frame of socio-technical affordances. Incitement to critique is viewed here as a particular kind of affordance.

Social media platforms shape rather than facilitate social acts. ${ }^{42}$ Platform features, functionality, ToS and the localized practices of using the platform incite specific practices, discourses, and perceptions. As we demonstrate shortly, NSFW on Tumblr incites distinct practices and perceptions around content production and consumption, relationships, intimacy, affect, and (sense of) community, which we condense into three broad categories: practices of interaction, representation, and interpretation.

The framework of affordances is increasingly popular among communication scholars, albeit in use since the late 1970 s. ${ }^{43}$ In recent years, some exciting extensions focused on the differences between affordances, features and outcomes, the range of affordance, the specific mechanics of how affordances function, and high- and low-level affordances have been developed. ${ }^{44}$ Synthesizing existing work, we define social media affordances as perceived (i.e. relational to the individual user) possibilities for actions. 
For analytical purposes we differentiate social and technical aspects of affordances: the first indicating the perceived possibilities of actions as relational to social networks entangled with that action (i.e. how does the sociality of the situation afford the action) and the second indicating the perceived possibilities of actions in relation to the platform as a technological artifact or interface. Affordances can additionally be specified in terms of the preferred actions (i.e. affordances for what). The term social (also interactional and communicative) affordance has also been used in this literature, now indicating affordances for sociality.

We are interested in analyzing both the social and technological aspects of the affordances that particular social media communities (in this case, NSFW on Tumblr) have for particular actions (such as those instantiating critique). By looking at the affordances not only of the Tumblr platform, but also of the community/culture of NSFW on Tumblr, we focus on the assemblage of social and technical affordances. Further, we look for what in this assemblage affords critique and hypothesize that it lies in some enmeshing of the socio-technical platform affordances and the affordances for specific types of sociality and communication.

\section{How does NSFW on Tumblr afford critique?}

We conducted a meta-analysis of previous analyses of informants' practices to evaluate whether the events documented in fieldwork warrant description as critique in Foucault's sense. For this, we relied on Adele Clarke's method of mapping, and Annette Markham's development of Clarke's approach. ${ }^{45}$ Mapping is an iterative process, yielding "thick analysis" of situations. Situational maps focus on what participants and/or the researcher consider relevant human, non-human, or discursive elements of a given situation. Relational maps focus on the relations between elements and on what centralizing and decentralizing elements illuminates or obscures about these 
relationships. ${ }^{46}$ We created multiple maps, starting from messy situational maps that answer the questions of who and what are in and matter within the situation; moving to ordered maps; and then to relational maps ${ }^{47}$ We mapped each situation where empirical material indicated critique of the normalization of clusters of norms: where the participants reported, or the researcher observed, practices that seemed to question body-normativity, hetero-normativity, mono-normativity, kink-shaming, and narrow versions of feminism.

Figure 2 gives an example of one of the many maps created to understand the critical elements of a particular experience (taking and sharing sexy selfies), and the perceived impacts of that experience on informants' dispositions. This map indicates a number of salient attributes to the experience of critique. Among these are platform affordances, platform affects, perceived sense of social distance or intimacy; adoption, reinterpretation, and development of mediated practices; embodied and corporeal experiences, relationships, cultural norms and sense of community.

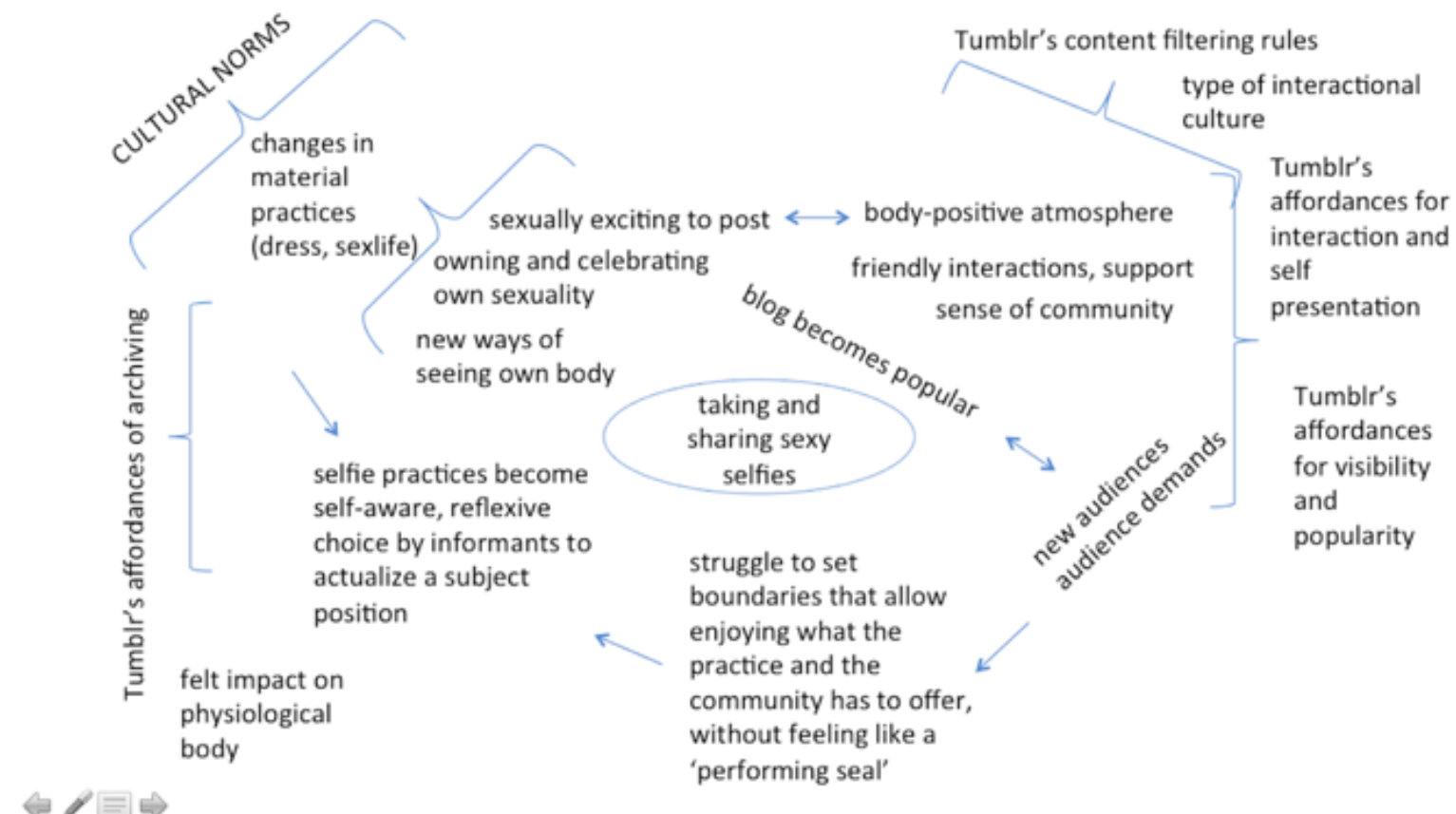


Figure 2: Example of situational map

To address the central question of what affords rejecting the normalization of hetero-, body-, and mono-normative sets of norms in NSFW Tumblr, we followed the initial situational mappings by creating a concept map (Figure 3). It abstracts to the dynamic interplay of elements that emerged and recurred as relevant for facilitating critique across the different situational maps of NSFW Tumblr.

\section{PERCEIVING THE PLATFORM AS A TECHNICAL STRUCTURE}

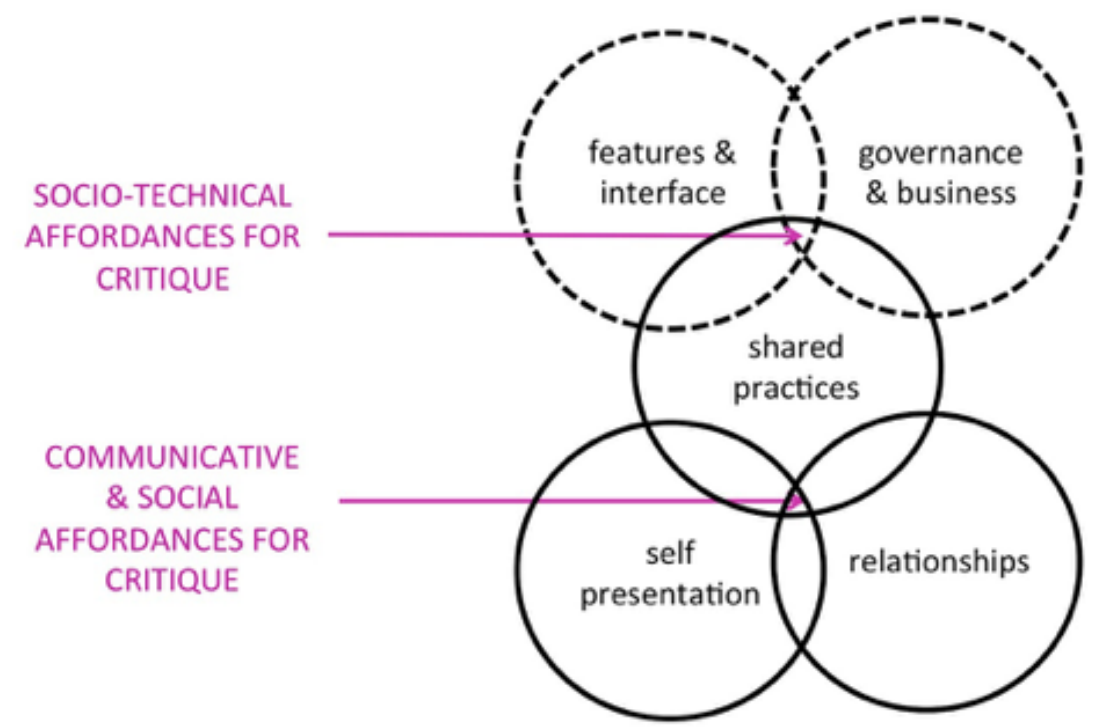

USING THE PLATFORM

Figure 3: Map of what facilitates critique on NSFW Tumblr.

Our informants used two explanatory narratives to articulate why and how NSFW on Tumblr is conducive to critique. The first narrative concerns the platform as a corporate technological structure, and the ways it is experienced as such via its interface, ToS, changes in content moderation policies, and speculations about corporate interests. The intersection of shared practices, platform features, and governance in Figure 3 is where we see the socio-technical affordances for critique emerging. The 
second narrative centers on using the platform. This narrative is articulated primarily through descriptions of self-presentation; interactions with others, their content, and ideas; and relationship creation and affect. The intersection of shared practices, selfpresentation, and relationships on the platform in Figure 3 is where the affordances for the type of communication and sociality that make critique possible emerge. These two narratives are tightly interconnected. Within this interactional situation, the technical features of the interface afford certain styles and forms of self-presentation and interaction, from which specific interactional norms and a sense of community emerge. The critical affordances of NSFW on Tumblr therefore arise from what people think the platform allows them to do, what its possibilities for social interaction are, and how the shared practices of social interaction and self-presentation are experienced in relation to sets of norms.

\subsection{Platform as a technological structure}

Tumblr is a microblogging platform. Logged on users create often-pseudonymous accounts, which allows them to post original multimodal content and reblog content posted by others and to follow a range of other blogs the content of which coalesces into a feed on the users' dashboard. The reblog button, enabling users to publish content from another blog onto their own with one click, is perhaps the platform's calling card. It is possible to view Tumblr blogs without having an account or being logged on, either via URLs or by using the Tumblr search function. Content is diverse and there are many different communities. Navigating and identifying these communities presumes immersion: the boundaries of communities are discursive and psychosocial rather than technical.

For the majority of the fieldwork period, Tumblr's ToS Guidelines, FAQ and content moderation policies explicitly allowed NSFW content. ${ }^{48}$ Tumblr called this a 
"live-and-let-live kind of a thing." ${ }^{49}$ Individuals were positioned as responsible for both avoiding content and making it avoidable, obliging NSFW bloggers to tick a box filtering their content from search results for logged-in users who have opted into "safe mode," and excluding it entirely from non-logged in searches. However, compliance was not diligently policed. The platform did not "recommend" NSFW content, but they did not, prior to the Verizon acquisition, block NSFW search terms either. Tumblr makes its revenue via ads and sponsored posts, so our participants assumed that the numbers NSFW blogs and their audiences generate were an important part of business ${ }^{50}$ However, this content is unpalatable for most advertising clients. Until mid2017, and more so until the end of 2018, Tumblr seemed to address this tension at the level of individual blogs rather than overall accessibility of sexual content. This approach played an important part in making critique as described here possible.

Regarding the interface and technological features of the platform, the following three are most pertinent here. First, reblogging allows nuanced interaction, simplifies connecting with strangers -as one of our participants observed, it is much easier to reblog someone's selfie with a compliment than to send them a message — and introduces curation into self-presentation (i.e. the reblogged third party content becomes self-referential and self-representational). ${ }^{51}$ At the same time, reblogging renders the shared content a marker of the community, facilitating liquidity around authoriality and rendering Tumblr a co-constructed representational space. Second, Tumblr does not make people fill out a set of pre-given questions from drop-down menus, the users are not presented via structured profiles, which also invites creative expression. ${ }^{52}$ It counters the presumption evidenced by other platform interfaces (e.g. Facebook) that a person is most succinctly categorized by their age, sex, and location. Third, there is no integrated commenting, which limits abuse and trolling. Finally, the messaging system 
has multiple options for conversing (anonymously, pseudonymously, publicly, privately, mono- or dialogically), thus lubricating interaction and relationship-building based on common aesthetics, preferences, lifestyles, or interests.

\subsection{Using the platform: Representational, interpretive and interactional practices}

Our participants invoke the notion of community in their narration of their experience, emphasizing Tumblr's body-, kink-, and queer-positive "vibe." They point out that the community shares a communicative style, operating with an accelerated, yet partial, intimacy. This sense of community is to a significant extent attributed to the normative dynamics around NSFW self-presentation. Due to the contestable status of NSFW content (i.e. that public, non-monetized nudity is shameful), creating and posting it presumes a certain amount of assumed trust. ${ }^{53}$ This assumed trust in turn relies on and produces specific forms of relating to other people and their content. We now zoom in to the center of the conceptual map in Figure 3 to explain some of these shared practices in detail.

Zooming into the shared practices, we offer a magnified map in Figure 4 and highlight three types of shared practices which are particularly conducive to critique: representation, interpretation and interaction, all of which have a shared aesthetics/ethics. 


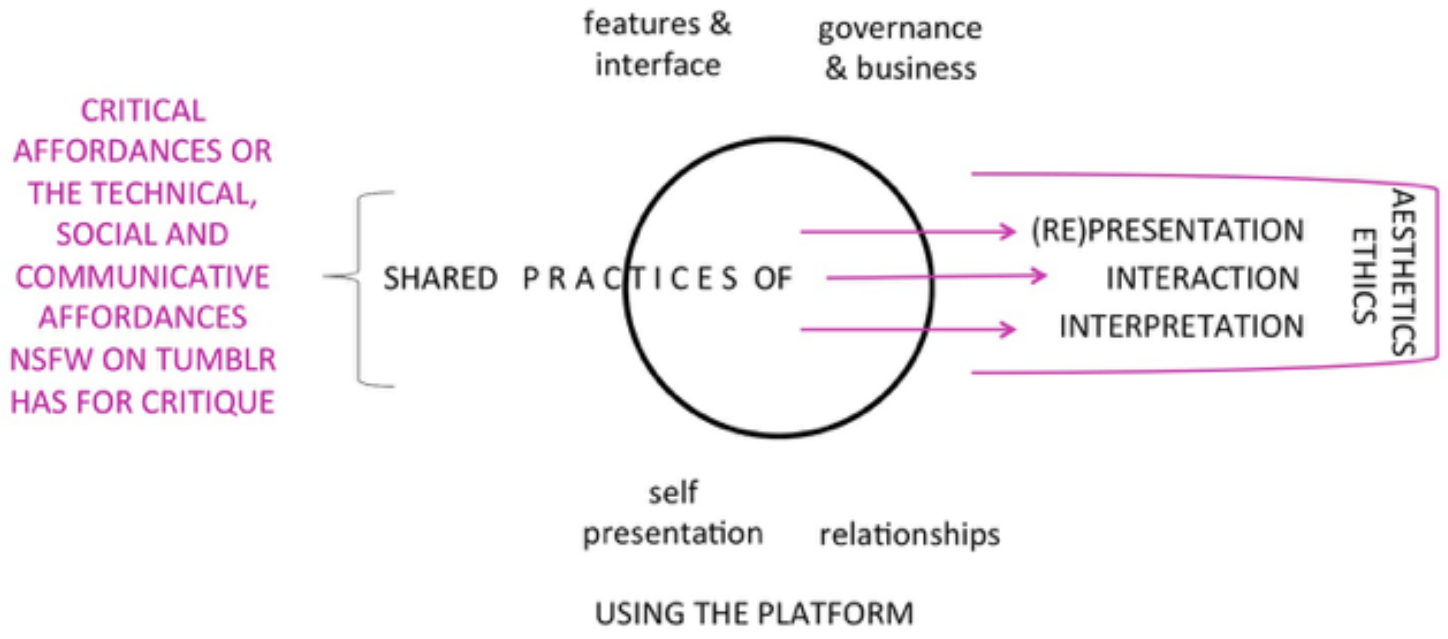

Figure 4: Map of shared practices on NSFW on Tumblr

(Self)-representation in NSFW on Tumblr is best conceptualized not as semantic reference via discrete units of content, but as practices or performances bound by localized community literacies. Our definition of self-representation, partly developed on this same Tumblr data, foregrounds indexicality, identity-work, and community. We define (self)-representation as a set of emergent, intertextual practices of content production and consumption, recognized by both producers and audiences as flexible statements of identification. ${ }^{54}$ Shared practices of representation are, in this context, inextricably entangled with shared practices, norms, and conventions of interpretation and interaction.

One of our participants selfie's -an image of a naked woman lying on a hotel bed, with her head cropped out of the frame - can illustrate this. Within the community of NSFW selfie enthusiasts the image is intended and interpreted as "sexy." Depending 
on the caption, the hashtags and the compositional features (color, filters, photo edits, accessories in the image and so on), it might also be intended and interpreted as beautiful, poetic, funny, or cute. In this case, the caption read "clothes are a violence, look at the scars they leave," 55 inviting a more serious interpretation, whereas the same person has posted similar nude selfies in a similar setting (i.e. bed) captioned with song lyrics, flirty invitations to the imagined viewer, autobiographic confessions, and jokes. While the "formal" logic of self-representation (the content of the image, the posing of the body, the composition) emulates pornography/erotica, it is remixed with the visual logic of the genre of selfies (indexical of the gesture of me showing you me), and various subcultural signifiers (props that function as metacommunicative signs, of anything from Star Wars fandom to nature-loving nudism). ${ }^{56}$ The caption of the image and the rest of the content on the blog intertextually frame the image, imbuing the amateur, subcultural, selfie-pornographic representational logic with additional intimacy, vulnerability, humor, snark, and so on. Interpreting this image as "sexy" or "cute" or "funny" thus involves a certain literacy, resulting from personal and witnessed experiences of the interactions surrounding images, and from what posters say about what it feels like to expose themselves in this way.

In terms of the style of interpersonal interaction (likes, reblogging with added captions, interacting privately using Chat, or publicly via Ask and Submit), informants highlight the "do unto others as you would have them do unto you" principle. Bodyand appearance-criticism, intolerance of other people's sexuality, disregarding people's instructions about how they want their content treated (e.g. no caption stripping, or no reblogging), or appropriating content go against the norms of the community. Compliments, empathy, and public expressions of happiness for other people's wellbeing are valued. In practice, this normative tolerance, perhaps because enacted in a 
sexually explicit context, often takes the form of a flirty, intimacy-signaling interactional style.

We can describe three broad modes of interpretation, distilled from how our informants said looking at other people's images made them feel, or what they thought the photographers intended.

1. An empathic interpretation focused primarily on the known or imagined context of image production. "I love this picture, she was so happy that day, you can see that she is not self-conscious and see a real smile, $" 57$ one of our participants said while looking at an image of another. Images were commonly interpreted as defiance, as recordings of happy moments, as documentations of realizations about the self, or as antidotes to how that person is "read" in other contexts (a mom, an educator etc.). These interpretations emerge from immersion within a flow of captioned, contextualized self-representational posts, alongside personal experience of taking and sharing images of one's own body.

2. A participatory interpretation carries the viewer's visceral response into the image: they imagine themselves as the person photographed, or as the person responding to the (sexual) invitation in the picture.

3. A more detached, cultural-consumption response is characterized by the viewer finding the image or the pictured person aesthetically appealing, or their selfpresentation in some way impressive.

These interpretations do not hinge on inherent semantic references in the image. ${ }^{58}$ That an image is interpretable as "sexy" is not necessarily self-evident to outsiders. To those outside the shared local practices of representation, interpretation and interaction, the same image could be read variously as self-objectifying (e.g. by conventional feminist analysis, trained on the commodification of the dismembered 
female body in advertising), as pornographic (e.g. by those whose literacy of erotic imagery is based in pornography), as shameful (e.g. by association to revenge porn and leaked celebrity “nudes”), or simply as cryptic.

Now, to return this account to the Foucauldian formulation of critique, we describe below how these entangled practices of representation, interpretation, and interaction are immanent to a particular ethics and aesthetics.

\section{The aesthetics and ethics of critique}

Described predominantly in the 1981-1984 lectures, published in English in The Hermeneutics of the Subject and The Courage of Truth, the aesthetics of existence refers to the pursuit of an existence as an "object of aesthetic elaboration and perception (...) as a beautiful work." 59 "Work" is best taken as noun and verb here, as artisanal practice. The aesthetic of existence is an ongoing, self-reflexive practice of a self's relationship to self, which Foucault names as ethics. There is a logic to Foucault's use of the term aesthetics with reference to an ethical practice. As explained by Frédéric Gros, what Foucault "finds in ancient thought is the idea of inserting an order into one's life, but an immanent order neither sustained by transcendent values nor externally conditioned by social norms. ${ }^{60}$ Foucault was fascinated by and working towards articulating a nonjuridical, non-authoritarian, non-obligatory ethics, centered on a personal practice towards making one's life a work of art, which he considered the "final point of resistance to political power." ${ }^{61}$ He called this the aesthetics of existence. To get there, Foucault built on the Cynics for the philosophical concept of parrhesia, and from the 19th century idea of "the artistic life as the condition of the work of art, as authenticating the work of art, as work of art itself." ${ }^{22}$ Foucault defines parrhesia as "frankness, open-heartedness, openness of thought," both in terms of an ethos or moral quality of telling truth about one's self, and in terms of a technique for speaking the 
truth to "the other in such a way that this other will be able to form an autonomous, independent, full and satisfying relationship to himself." 63

PERCEIVING THE PLATFORM AS A TECHNICAL STRUCTURE

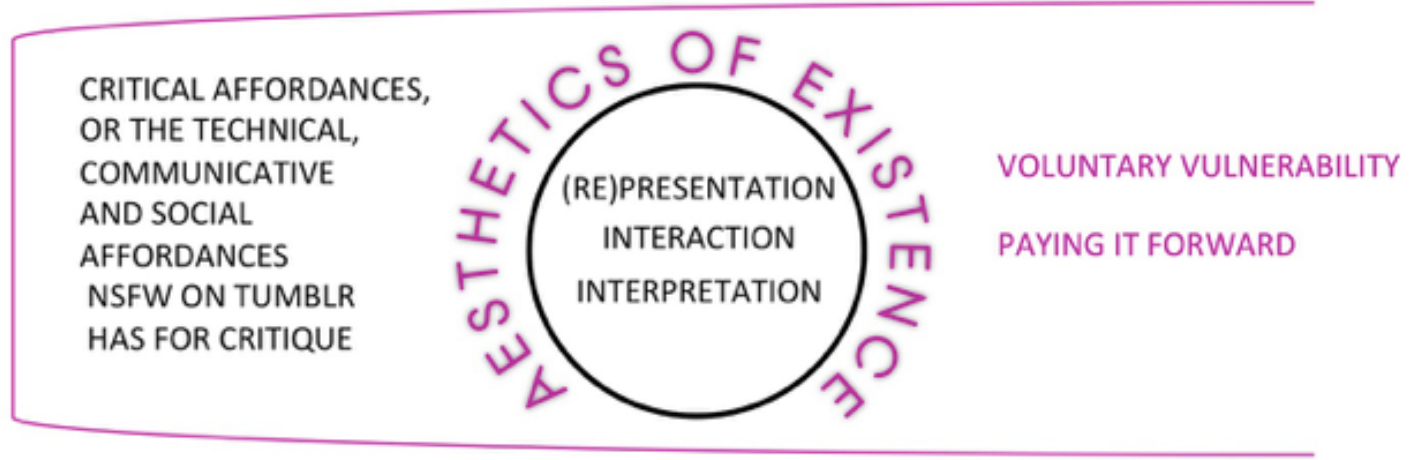

USING THE PLATFORM

Figure 5: Map of the aesthetics of existence on NSFW on Tumblr

The critical affordances of NSFW on Tumblr are immanent to the shared practices of representation, interpretation, and interaction among the community. From these, a shared aesthetics|ethics emerges, also immanent to these practices, and manifested in particular forms, discussed below. As depicted in Figure 5, the technical, social, and communicative affordances of NSFW on Tumblr shape the community's shared practices. From these practices, as from all others, some conventions, or even local norms, emerge, and in turn, shape and constrain representation, interpretation, and interaction into an aesthetic and ethical practice. Informants are not merely representing 
their naked bodies, interpreting representations of those of others, and interacting with each other. They are also, almost as an unintended consequence, working on their selves (that is, undertaking an aesthetics of existence). ${ }^{64}$ Resisting dominant norms, then, depends on the emergence of localized micro-norms. When practices of representation, interpretation, and interaction inter-articulate with this ethic, informants start enacting, noticing, and experiencing them as specific, conscientious practices. Key examples are the practices of voluntary vulnerability and paying it forward.

Voluntary vulnerability refers to the continued posting of NSFW selfies despite cognizance that sharing them makes the sharer multiply vulnerable. Nude and sexual self-expression is morally and legally regulated in most societies: sharing nudes puts one at risk of moral shaming at least. It also exposes the body, opening one up to the criticism so familiar from internet commentary and the fashion and beauty industry. Further, the image captions, hashtags, and text posts framing those bodies often aspire towards (partial) sincerity and authenticity. Insights into one's lifestyle, fantasies, insecurities, anxieties, and the relations between these are offered, further opening the sharer up to abuse. Our participants are cognizant of this, but see their voluntary vulnerability as aiding in their critical self-awareness and self-transformation. "The feedback I get and the interactions I have with people are deeper when I am reasonably sincere in what I post," a participant said, while another one spoke of the importance of revisiting and contemplating their previously posted anxieties. This vulnerability, as well as it mostly remaining unabused, constitutes a recognizable and preferred aspect of the shared culture of the community, described by a participant as: "we all overshare, it's ok here, that's what we have in common." It exemplifies a norm or ethic of care (for oneself, other individuals, and the community) and evidences the sustained enactment of that norm. Voluntary vulnerability is further politicizing in the sense that, as a 
public/private practice, it short-circuits and serves as a resistant meta-commentary on the shaming and policing of erotic and sexual expression.

Paying it forward refers to the conscious choices informants make to give others mindful feedback; boost their confidence when doing so seems apposite; post and reblog queer, non-white, non-thin, scarred, non-able bodies; or use one's popularity to question some forms of thinking or to unsettle stereotypes with details of lived experience. This usually develops gradually, initiated by a recognition of how one's own perceptions have changed as a result of participation in NSFW Tumblr. ${ }^{65}$ This is a form of coming to political consciousness and practicing forms of action expressing that consciousness. It involves recognizing the context of embodied and mediated erotics as pedagogical and political, re-interpreting one's own experiences, desires, and intimate relations as political in the same way, and re-aligning one's behavior accordingly.

Exploring how representation, interpretation, and interaction develop into voluntary vulnerability and paying it forward points to a means of differentiating a digital experience with critical potential from one without. Returning to the language of affordances: when we are interested in affordances for critique, we can look for affordances for the emergence of (local norms that generate) self-reflexivity and parrhesia. These provide a key to the nascent capacity to interrogate the normalization of hegemonic norms. We have shown that between 2011 and 2017, NSFW on Tumblr had these affordances for critique. Is this now changing?

\section{Death of a heterotopia?}

In December of 2018, Tumblr announced it would ban all "photos, videos, or GIFs that show real-life human genitals or female-presenting nipples, and any content (...) that depicts sex acts." ${ }^{\prime 66}$ Many blogs outside of the supposedly targeted porn accounts were flagged by predictably inept automated content moderation mechanisms. The CEO's 
rhetorical framing of their commercially motivated decision as coming from a desire to be a "safe place" is deeply ironic, given they are effectively erasing, silencing and evicting communities for queer youth, fandoms, art creators, sex workers and NSFW diarists, with limited alternatives. ${ }^{67}$ Based on preliminary research of reactions to the Tumblr ban some self-professed "Tumblr refugees" were trying Twitter, while others opted for lesser-known blogging platforms like Pillowfort or Dreamwidth, or more specific sites like Newgrounds, bdsmlr (created specifically to host Tumblr evictees with interests in BDSM), or PornHub (who were very vocal in inviting people to their site). ${ }^{68}$ Instagram and Facebook have been known for censoring "female presenting nipples" for years, and Facebook for also demanding real name accounts, so these were not popular alternatives. The platforms explored by the "refugees" are all distinct in their organization and affordances. It remains to be seen what cultures burgeon on these platforms.

However, we have shown that in the case of NSFW on Tumblr, the potential for critique arose out of a confluence of social and technical conditions, which evolved over time in an entangled manner -some make possible the others, which in turn fertilize the next. This is not an impossible confluence to establish, but not a self-evident one either. Pseudonymous yet long-term accounts, curatorial self-representation, a layered system of interaction, a culture of tolerance, a formation of communities (not merely hashtag publics), voluntary vulnerability, and a desire to pay it forward all coalesced into what Tumblr afforded in terms of questioning the status quo. Crucially, it did so while maintaining its identity as a social media platform, rather than a porn site or a fanfiction forum, thereby maintaining accessibility and the heterogeneity of the userbase (compare having a Tumblr app on your phone, as opposed to having a PornHub or bdsmlr). 
This decision shows Tumblr managers' lack of awareness or concern for the fact that, as we have described in detail above, NSFW cultures on non-porn platforms often have great educational and political potential. Before, Tumblr could have been considered one of the few remaining spaces within the monopolizing, platform-regulated social media ecology that was experienced and used as community-oriented, creative, and safe for non-normative or marginalized users. Parts of Tumblr, were, perhaps, heterotopias. The illustrative example par excellence of heterotopia, for Foucault, was the boat. He wrote: "In civilizations without boats, dreams dry up, espionage takes the place of adventure, and the police take the place of pirates." ${ }^{69}$ It is certainly possible that different kinds of critique associated with different kinds of normative marginality will emerge on Tumblr, but the initial three months of post-ban observation indicate that this particular culture of critiquing these particular sets of heteronormative norms is disintegrating. Many participants have left; others still have their blogs, but are no longer posting. While the full effects of the NSFW ban are yet to unfold, we are concerned that Tumblr's decision will contribute to the overall impoverishment and homogenization of discourses on social media, impacting adversely on its critical potential.

\section{Affordances of theory}

Foucault has drawn no shortage of critical ire. It has been argued that his description of the relationship between power and resistance is contradictory; trapped in a vicious cycle between the two. ${ }^{70}$ The standard critical position asserts that his thinking lacks space outside of power, presenting impoverished accounts of the integrity of the subject and of normative ethical imperatives. ${ }^{71}$ Foucault's (ambiguous, perhaps cyptonormative) antinormativity is taken to mean that, as a resource, his work is untenably normatively thin. ${ }^{72}$ 
Both the standard critiques of Foucault, and his formulations of normativity and antinormativity, have been elaborated, contested, and extended in queer theoretical work. Foundational texts from Michael Warner and David Halperin defined queer as inherently relational and resistant to the norm. ${ }^{73}$ Yet, as queer theory established itself, its engagement with normativity came under scrutiny. Scholars began arguing that queer theory's commitment to antinormativity has itself become normative. ${ }^{74}$ This interpretation has, in turn, been critiqued as empirically untethered and politically acquiescent. ${ }^{75}$ We do not aspire to assert a definitive exegesis of Foucault here; nor do we wish to enter into the well-established fray of claims and counterclaims of misreadings of his work. As empirical sociologists, we need to operationalize Foucault's ideas into a conceptual heuristic, which aids in understanding and explaining specific social and cultural practices and forms. For us, then, the debate about Foucault's merits serves as an opportunity to elucidate the affordances of mobilizing Foucauldian critique in an account of NSFW Tumblr practices.

Part of the trouble can be traced to discrepant uses of the norm-related terminology, evident from the extensive history of work on norms in sociology. ${ }^{76}$ There is not one right way to use this register. The point rather lies in appreciation of the processes of normalization as situated operations, instantiating a matrix of power relations. While there are sets or networks of normalized and normalizing norms that at particular times, in particular places, and for particular groups of people - carry more disciplinary and regulatory weight than others, norms are not static: they are relational, multidirectional, and polyvalent. People routinely enact and traverse normative matrices, playing different norms against each other. Coming to critique dominant norms for our respondents was inextricably connected to participation in local normative forms of sociality. The empirically and politically valuable feature of 
Foucault's thinking is the refusal of commitment to a priori normative conceptions of the good. Instead, focus is drawn to the role played by critique in the ongoing reconfiguration of a particular network of norms. ${ }^{77}$ It is this precise feature of his work which contributes to the diversity in how Foucault's thinking can be used and explains why his antinormativity and his ostensible ethical neutrality can be discussed both as assets and liabilities.

John Muckelbauer argues that the negative responses to Foucault emerge out of a "programmatic reading," assuming there is only one, predetermined, universal mode of resistance. ${ }^{78}$ If resistance is understood as responding to specific power relations, and critique to particular dominant norms, it becomes possible to recognize and consider each attempt at critique in its context. This precludes dismissing techniques of critique or practices of resistance as such for their failures against other normalizing norms or power relations and imposing contextually inappropriate evaluations of resistance.

\section{Conclusion}

Critique is always dynamic, situated, embedded, and contextual; responding to some particular structure of normation rendering it intelligible and critical as such. Critique is not totalizing and does not respond to or arise from a monolithic form of power, but rather from "an archipelago of different powers that maintain their specificity." Critique is local. In Foucault's terminology, critique arises in problematization, the process whereby some phenomenon comes to be thought, recognized, and described as a problem. ${ }^{80}$

This notion sheds light on why Foucault is appropriate to the description and valuation we set out here of NSFW on Tumblr and why the recent NSFW ban is a cause for concern. Above, we described how the interaction between platform, use practices, and emerging ethics leads to social dynamics conducive to relatively public expression 
of, and support for, often marginalized practices and (sexual) subjectivities, and critique of normative practices which police, shame, and subjugate those practices and subjectivities. We showed how the technical, social, and communicative affordances of NSFW on Tumblr shape the community's shared practices, how localized norms and conventions emerge from these practices, and how these, in turn, shape and constrain an aesthetic | ethic. Those of us interested in social media platforms' affordances for critique can look for affordances for self-reflexivity and parrhesia, as these evidently increase collective capacity to problematize the normalization of hegemonic norms.

Problematization, as Foucault describes it, is "the totality of discursive or nondiscursive practices that introduces something into the play of true and false, and constitutes it as an object for thought." ${ }^{81}$ For some community members, engagement with the NSFW Tumblr context culminated in expressions and practices of critique: new forms of politicization, new ways of being, relationally, with (respect to) others. Instead of dismissing the lived effects and implications of the heteronormative norms as haphazard, individual troubles below the radar of political consciousness or collaborative response, those community members are now inclined to directly address them as social and political phenomena.

There are several reasons why we find engaging with Foucault productive and practical for explaining the political and sociological salience of critique on NSFW Tumblr. Perhaps most importantly, this way of thinking about critique works as realpolitik: both a form of description and a way of "seeing" social dynamics in the world. It functions as an analytical pragmatics of critical action and speech, acknowledging that we cannot and should not assume a utopian teleology to critical practice, but are rather constantly contesting, being pulled and pulling this way and that, in relation to different power structures, and in the co-articulation of different, emergent 
normative conceptions of the good. It helps us to keep in mind that the conception of the good is not fixed or unitary and that contingent processes of political articulation are often more sociologically vital and important than the "closure" of established or predetermined normative ends.

As a conceptual framework, it thus provides us with a sensitivity or receptivity in orientation, at the interpretive and analytical level, to local problematizations: to models of critique and of what is to be critiqued, being developed and applied in the communities we research. In this instance, we share with our respondents a sense of the validity of their critical practice: we believe their objections are sound; their responses are valid and effective. We think their practice is politically significant. As ethnographers, however, the model of critique Foucault espouses is particularly valuable to us, in that it invites us to think through how our respondents see, negotiate, and politicize the inequities they experience, and to develop an appreciation of how that problematization develops across the different contexts of their lives.

Notes

1. Michel Foucault, "What is Critique?" in The Politics of Truth, trans. Lysa Hochroth, ed. Sylvère Lotringer, and Lysa Hochroth (New York: Semiotext(e), 1997), 41-82.

2. Tumblr was established in 2007. In 2019, it hosted around 457 million blogs. Tumblr, “About,” https://www.tumblr.com/about (accessed February 19, 2019). Until December 2018, Tumblr was known for relatively lax content filtering policies regarding sexual content, allowing NSFW communities to prosper.

3. We are drawing primarily on Foucault's late work, particularly the essays based on the 1978/79, 1981/82, and 1983/84 lectures: Michel Foucault, The Birth of Biopolitics: Lectures at the Collège de France, 1978-1979, trans. Graham Burchell (London: Palgrave Macmillan); 
Michel Foucault, The Hermeneutics of the Subject: Lectures at the Collège de France, 19811982 (London: Palgrave Macmillan, 2005); and Michel Foucault, The Courage of Truth, The Government of Self and Others II: Lectures at the Collège de France, 1983-1984, trans. Graham Burchell (London: Palgrave Macmillan, 2011).

4. Sandra Evans, Katy Pearce, Jessica Vitak, and Jeffrey Treem, "Explicating Affordances: A Conceptual Framework for Understanding Affordances in Communication Research," Journal of Computer-Mediated Communication 22, no. 1 (2017): 35-52; Jenny Davis and James Chouinard, “Theorizing Affordances: From Request to Refuse,” Bulletin of Science, Technology and Society 36, no. 4 (2016): 241-248; Peter Nagy and Gina Neff, "Imagined Affordance: Reconstructing a Keyword for Communication Theory," Social Media and Society 1, no. 2 (2015): 1-9; Taina Bucher and Anne Helmond, "The Affordances of Social Media Platforms," in The Sage Handbook of Social Media, ed. Jean Burgess, Alice Marwick and Thomas Poell (London: Sage, 2017), 223-253.

5. The material analyzed for this article consists of multiple interviews (up to 5 per informant) with 30 informants, group interviews, blog outtakes and selfies, and ethnographic fieldnotes from research conducted 2011-2018.

6. For influential accounts of these normative regimes, see Gayle Rubin, “Thinking Sex: Notes for a Radical Theory of the Politics of Sexuality," in Social Perspectives in Lesbian and Gay Studies: A Reader, ed. Peter Nardi, and Beth Schneider (London: Routledge, 1984), 100-133; Pat Califia, Public Sex: The Culture of Radical Sex (Pittsburgh: Cleis Pr, 1994); Lauren Berlant and Michael Warner, "Sex in Public," Critical Inquiry 24, no. 2 (1998): 547-566; Michael Warner, Fear of a Queer Planet: Queer Politics and Social Theory (Minneapolis: University of Minnesota Press, 1993); David Halperin, Saint Foucault: Towards a Gay Hagiography (New York: Oxford University Press, 1995); and Judith Butler, Bodies that Matter: On the Discursive Limits of Sex (London: Routledge, 2011).

7. Katrin Tiidenberg and Susanna Paasonen, "Littles: Affects and Aesthetics in Sexual Age-play," Sexuality and Culture, (2018); Katrin Tiidenberg, “There's No Limit 
to Your Love - Scripting the Polyamorous Self," Journal für Psychologie, 22, no.1 (2014): 1-27.

8. Katrin Tiidenberg, "Bringing Sexy Back: Reclaiming the Body Aesthetic via Self-shooting," Cyberpsychology: Journal of Psychosocial Research on Cyberspace 8, no.1 (2014): np.

9. Katrin Tiidenberg, "Queering Friendships - Blurred Lines of Relationships on Tumblr," in panel "Making and breaking rules on the internet," Select Papers of Internet Research (2016) https://spir.aoir.org/ojs/index.php/spir/article/view/8716 (accessed March 27, 2019). 10. Katrin Tiidenberg and Edgar Gomez-Cruz, "Selfies, Image and the Re-making of the Body," Body and Society 21, no.4 (2015): 77-102.

${ }^{11}$ Foucault, "What is Critique?".

12. Katrin Tiidenberg, “'Nude Selfies til I Die' - Making of Sexy Selfies,” in Sex in the Digital Age, ed. P.G. Nixon and Isabel Dusterhoft (London: Routledge, 2017): 78-89.

13. cf. Tiidenberg and Paasonen, "Littles”, Tiidenberg ,"There's no limit," Tiidenberg, "Bringing," Tiidenberg, "Nude selfies,” Tiidenberg, "Queering friendships,” Tiidenberg and Gomez-Cruz "Selfies,"

14. For discussion of these concepts, see, respectively: Leah Lievrouw, “Our Own Devices: Heterotopic Communication, Discourse, and Culture in the Information Society 1," The Information Society 14, no. 2 (1998): 83-96; Elizabeth Wood, “Consciousness-raising 2.0: Sex Blogging and the Creation of a Feminist Sex Commons," Feminism and Psychology 18, no. 4 (2008): 480-487; Amy Muise, “Women's sex blogs: Challenging Dominant Discourses of Heterosexual Desire," Feminism and Psychology 21, no. 3 (2011): 411-419; and Bryce Renninger, “'Where I Can Be Myself... Where I Can Speak My Mind’: Networked Counterpublics in a Polymedia Environment," New Media and Society 17, no. 9 (2015): 151329.

15. Leah Lievrouw, Alternative and Activist New Media (Cambridge: Polity, 2011), 19.

16. As evidenced in work on trolling and alt right practices: Adrienne Massanari, "\#Gamergate and The Fappening: How Reddit's Algorithm, Governance, and Culture Support Toxic 
Technocultures," New Media and Society 19.3 (2017): 329-346; Robert Mejia, Kay

Beckermann, and Curtis Sullivan, "White Lies: A Racial History of the (Post) Truth,"

Communication and Critical/Cultural Studies 15, no. 2 (2018): 109-126.

17. Foucault, "What is Critique?" 47.

18. Jana Sawicki, "Freedom," in The Cambridge Foucault Lexicon, ed. Leonard Lawlor and John Nale (Cambridge: Cambridge University Press, 2014), 159.

19. Christopher Penfield, "Critique," in The Cambridge Foucault Lexicon, 89.

20. Johanna Oksala, "Resistance," in The Cambridge Foucault Lexicon, 434.

21. Foucault, "What is Critique?" 47.

22. Michel Foucault, The History of Sexuality: An Introduction, Volume I, trans. Robert Hurley (New York: Vintage, 1990), 139.

23. Charles Taylor, "Foucault on Freedom and Truth," in Foucault: A Critical Reader, ed.

David Hoy (Cambridge, MA: Blackwell, 1986), 52.

24. Cited in Véronique Mottier, "The Invention of Sexuality," in Chic, Chèque, Choc:

Transactions Autour des Corps et Stratégies Amoureuses Contemporaines (Genève: Graduate Institute Publications, 2012), 32.

25. Lynne Huffer, Mad for Foucault: Rethinking the Foundations of Queer Theory (New York: Columbia University Press, 2010), 113.

26. Michel Foucault, History of Madness, trans. Jonathan Murphy and Jean Khalfa (London: Routledge, 2006), 88.

27. Rubin, “Thinking Sex”; Foucault, History of Madness, 88.

28. Foucault, History of Sexuality, 103.

29. Ibid., 23.

30. Ibid., 34; 116.

31. Foucault, "What is Critique?" 44. 
32. Michel Foucault, "What is Enlightenment?" in Ethics: Subjectivity and Truth, ed. Paul Rabinow (New York: The New Press, 1997), 316.

33. Sawicki, "Freedom," 156-162.

34. Michel Foucault, "The Ethics of the Concern of the Self as a Practice of Freedom," in Ethics: Subjectivity and Truth, ed. Paul Rabinow (New York: The New Press, 1997), 284. 35. Michel Foucault, Technologies of the Self: A Seminar with Michel Foucault, ed. Luther Martin, Huck Gutman, and Patrick Hutton (Amherst: University of Massachusetts Press, 1988), $16-49$.

36. Michel Foucault, "Sexual Choice, Sexual Act," in Ethics: Subjectivity and Truth, ed. Paul Rabinow (New York: The New Press, 1997), 141-156.

37. Ibid., 151-152; 165-169.

38. Mark Kingston, "Subversive Friendships: Foucault on Homosexuality and Social Experimentation," Foucault Studies 7, (2009): 7-17.

39. Califia, Public Sex; Berlant and Warner, "Sex in Public"; Wendy Hui Kyong Chun, Control and Freedom: Power and Paranoia in the Age of Fiber Optics (Cambridge, MA: MIT Press, 2008).

40. Foucault, History of Sexuality

41. José Van Dijck, The Culture of Connectivity: A Critical History of Social Media (New York: Oxford University Press, 2013), 41.

42. Ibid., 29.

43. James Gibson, The Ecological Approach to Visual Perception (New York: Psychology Press, 2014); Donald Norman, The Psychology of Everyday Things (New York: Basic Books, 1988).

44. Evans, Pearce, Vitak and Treem, "Explicating Affordances"; Davis and Chouinard, "Theorizing Affordances"; Nagy and Neff, "Imagined Affordance"; Bucher and Helmond, "The Affordances of Social Media Platforms.” 
45. Adele Clarke, Situational Analysis: Grounded Theory after the Postmodern Turn (Thousand Oaks, CA: Sage, 2005); Annette Markham and Ane Gammelby, "Moving Through Digital Flows: An Epistemological and Practical Approach," in The Sage Handbook of Qualitative Data Collection, ed. Uwe Flick (London: Sage, 2017), 451-465.

46. Ibid.

47. Clarke, "Situational Analysis," 86-87.

48. Cf. Susanna Paasonen, Kylie Jarret and Ben Light, NSFW, Sex, Humor and Risk in Social Media (Cambridge, MA: MIT Press, forthcoming).

49. Tumblr, "Sensitive content," https://tumblr.zendesk.com/hc/enus/articles/231885248-Adult-content (accessed June 8, 2018).

50. A presumption held widely according to the December 2018 reactions to Tumblr's announcement of the NSFW ban.

51. Katrin Tiidenberg and Andrew Whelan, "Sick Bunnies and Pocket Dumps: 'Not-selfies' and the Genre of Self-representation," Popular Communication 15, no. 2 (2017):141-153.

52. Cf. Abigail Oakley, “Disturbing Hegemonic Discourse: Nonbinary Gender and Sexual Orientation Labeling on Tumblr," Social Media + Society 2, no. 3 (2016): np. For how LGBTQIA Tumblr users use their "bio" boxes.

53. Katrin Tiidenberg, "Boundaries and Conflict in a NSFW Community on Tumblr: The Meanings and Uses of Selfies," New Media and Society 18, no.8 (2016): $1563-1578$.

54. Tiidenberg and Whelan, "Sick Bunnies," 143.

55. Tiidenberg fieldnotes

56. Paul Frosh, "The Gestural Image: The Selfie, Photography Theory, and Kinesthetic Sociability," International Journal of Communication 9, (2015): 1610.

57. Tiidenberg interview

58. Frosh, “The Gestural Image.”

59. Foucault, The Hermeneutics of the Subject; Foucault, The Courage of Truth, 162. 
60. Frédéric Gros, "Course Context," in The Hermeneutics of the Subject, 530.

61. Foucault, The Hermeneutics of the Subject, 252.

62. Foucault, The Courage of Truth, 188.

63. Foucault, The Hermeneutics of the Subject, 169; 379.

64. Tiidenberg, "Bringing Sexy"; Tiidenberg and Gomez-Cruz, "Selfies."

65. cf. Tiidenberg "Bringing Sexy"; Tiidenberg "Nude Selfies."

66. Tumblr, “Adult Content,” https://tumblr.zendesk.com/hc/en-us/articles/231885248-

Sensitive-content (accessed February 10, 2019).

67. Tumblr had a recent conflict with the Apple App Store regarding their inability to adequately deal with child pornography, and a longer-term difficulty monetizing the platform where NSFW and SFW content co-existed. Tumblr, "A Better, More Positive Tumblr," https://staff.tumblr.com/post/180758987165/a-better-more-positive-tumblr (accessed February $10,2019)$.

68. Katrin Tiidenberg, "Nipples and Nazis at the \#TumblrIsDeadParty: Twitter Discourse on the Tumblr NSFW Ban" [JOURNAL INFORMATION NEEDED]

69. Michel Foucault, “Of Other Spaces (1967), Heterotopias," Michel Foucault, Info, https://foucault.info/documents/heterotopia/foucault.heteroTopia.en/ (accessed February 10, 2019).

70. Slavoj Žižek, The Ticklish Subject: The Absent Centre of Political Ontology (New York: Verso, 1999).

71. These critiques are condensed by John Muckelbauer, “On Reading Differently: Through Foucault's Resistance," College English 63, no. 1 (2000): 71-94.

72. Nancy Fraser, Unruly Practices: Power, Discourse, and Gender in Contemporary Social Theory (Minneapolis: University of Minnesota Press, 1989), 33.

73. Warner, Fear; Halperin, Saint Foucault. 
74. Robyn Wiegman and Elizabeth Wilson, “Introduction: Antinormativity's Queer

Conventions," differences 26, no. 1 (2015): 1-25.

75. Jack Halberstam, "Straight Eye for the Queer Theorist - A Review of 'Queer Theory

Without Antinormativity,," Bully Bloggers,

https://bullybloggers.wordpress.com/2015/09/12/straight-eye-for-the-queer-theorist-a-review-

of-queer-theory-without-antinormativity-by-jack-halberstam/ (accessed February 10, 2019).

76. Talcott Parsons, The Social System (London: Routledge, 2013); Jon Elster, The Cement of

Society: A Survey of Social Order (New York: Cambridge University Press, 1989); Niklas

Luhmann, “Are There Still Indispensable Norms in Our Society?” Soziale Systeme 14, no. 1

(2008): 18-37.

77. Janet Jakobsen, “Queer Is? Queer Does? Normativity and the Problem of

Resistance," GLQ: A Journal of Lesbian and Gay Studies 4, no. 4 (1998): 511-536.

78. Muckelbauer, "On Reading Differently."

79. Johanna Oksala, "Johanna Oksala on Foucault, Marx and neoliberal subjects," Theory,

Culture and Society 16, (2015), https://www.theoryculturesociety.org/johanna-oksala-onfoucault-marx-and-neoliberal-subjects/ (accessed February 10, 2019).

80. Michel Foucault, "Polemics, politics, and problematizations: an interview with Michel

Foucault," The Foucault Reader, ed. Paul Rabinow (New York: Pantheon, 1984), 389.

81. Michel Foucault, "The Concern for Truth," in Politics, Philosophy, Culture: Interviews and Other Writings, 1977-1984, ed. Lawrence Kritzman (New York: Routledge, 1988b), 257. 